\title{
Tannins in Artemisia: the hidden treasure of prophylaxis
}

\section{Opinion}

Proanthocyanidins (condensed tannins) are oligomeric and polymeric products of the flavonoid biosynthetic pathway. They are present in the fruits, bark, leaves and seeds of many plants, wine and teas, and are increasingly recognized as having beneficial effects on human health. They have attracted little interest in malaria research because in vitro they show no significant antimalarial activity. Anthocyanins and pro-anthocyanidins are responsible for the beautiful color of leaves in autumn and for the colors of fruits. The major sources of proanthocyanidins in the American diet are apples (32\%), chocolate $(18 \%)$ and grapes $(18 \%)$ There are not many data in the literature on the content of pro-anthocyanidins in food and plants, probably because of the difficulties to analyze them correctly. A rather complete table has been published by the US Department of Agriculture. ${ }^{1}$

For fruits and berries the highest content in $\mathrm{mg} / 100 \mathrm{~g}$ is found in blueberries (331), cranberries (418), blackberries (418), apples (120), plums (256) but very little in bananas, nectarines, mangos, peaches, pears, cherries, raspberries. In cereals and beans the leader by far is sorghum sumac (1900), various beans are around (500), but only small contents are found in barley and peas. In nuts and seeds, grape seed is the leader (3 500), hazelnuts are following with (500), pistachios (237), almonds (184), but only traces in peanuts, cashews. In spices the content is often very high: cinnamon (8100). It is not only the average content which is important, but the degree of polymerization may vary strongly from plant to plant: 1.61 for Trifolium repens, 3,57 for Pinus radiates needles, 7.39 for Lotus pedonculus, 8.1 for grape seeds, 34.9 for grape skin. ${ }^{2}$ In sorgho the degree of polymerization is higher than 10. In cranberries dimers and trimers predominate. It is very difficult to find studies on pro-anthocyanidins in Artemisia plants. In Artemisia afra very high concentrations were found: 1990 mg/100g. ${ }^{3}$ A recent paper deals with Artemisia herba alba and finds a concentration of $2100 \mathrm{mg} / 100 \mathrm{~g}$. ${ }^{4}$

Another paper detected the presence of anthocyanidins and tannins in several Artemisia species in Iran without quantifying them: A. absinthium, A.аnnua, A.biennis, A.diffusa, A.santolina, A turanica, A.vulgaris, A. sieberi. ${ }^{5}$ A more recent paper from Iran finds $340 \mathrm{mg} / 100 \mathrm{~g}$ in Artemisia аппиа leaves and only $30 \mathrm{mg} / 100 \mathrm{~g}$ in stems. ${ }^{6}$ A paper from Turkey finds an average of $420 \mathrm{mg} / 100 \mathrm{~g}$ of tannins in Artemisia absinthium. A study from Algeria compared the total extractable tannin content in some browse plant species. For Graminae they find an average of $600 \mathrm{mg} / 100 \mathrm{~g}$ DW, for Fabiaceae 400, for Artemisia campestris 5700 and for A.herba alba $3600 \mathrm{mg} / 100 \mathrm{~g} .{ }^{7}$ Tannin in $A$ absinthium varies significantly from one region in Tunesia to another, from 40 to $150 \mathrm{mg} / \mathrm{g} .{ }^{8}$ A study from Cameroon confirms that Artemisia plants are very rich in tannins. ${ }^{9}$ A recent analysis from Algeria finds an average of $2 \%$ proanthocyanidins in different solvents for Artemisia herba alba.$^{10}$ Another study finds $11 \%$ for Artemisia campestris and Artemisia herba alba. ${ }^{11}$ And another paper $8 \%$ for Artemisia absinthium. ${ }^{12}$

The big spread in analytical data of course is due to different analytical methods. A standardized technique needs to be defined
Volume 6 Issue 3 - 2018

Pierre Lutgen
IFBV-BELHERB, Luxembourg

Correspondence: Pierre Lutgen, IFBV-BELHERB, BP 98 L-6905, Niederanven, Luxembourg, Email lutgenp@gms.lu

Received: April 15, 2018 | Published: May 14, 2018

and implemented. Sodium bicarbonate enhances the extraction of tannins from medicinal herbs. The feature is used in Turkish tea houses. Some bicarbonate is added to the water used for decoction and the infusion becomes darker. ${ }^{13}$ Medicinal herbs, at least those with antimalarial properties, like Cymbopogon citratus (lemongrass) Vaccinium macrocarpon (cranberry), Aziradichta indica (neem), Cinnamomum verum (cinnamon) generally contain proanthocyanidins. An analysis of 11 plants in Brazil which are spontaneously used as medicinal plants reveals that their total tannin content is always high and ranges from 6800 to $13000 \mathrm{mg} / 100 \mathrm{gDW}$. Plants like Moringa oleifera or Panax ginseng who do not contain condensed tannins have no antimalarial properties. ${ }^{14}$ Artemisia plants and/or proanthocyanidins are known to decrease serum uric acid levels. ${ }^{15}$ All this would mean that Artemisia plants are very high in condensed tannins. A property which has been ignored and deserves further study. But why have they been ignored? The reason may be simple: $95 \%$ of the Artemisia extracts of Artemisia plants in the research papers are obtained with organic solvents, and tannins are insoluble in organic solvents like chloroform, hexane, benzene, ether and are sparingly soluble in ethyl acetate. The polymeric nature of proanthocyanidins makes their analysis and estimation difficult. For this reason, little is known about their consumption, although they likely contribute a large part of the daily polyphenol intake.

The antioxidant properties of plants are to a large extent related to their content in proanthocyanidins. Their antioxidant capacities are higher or comparable to vitamin $\mathrm{C}$ or E. ${ }^{16}$ Antioxidant activities depend on their configuration and degree of polymerization. In the aqueous phase, they increase from monomer to trimer and decrease from trimer to tetramer. Galloylation and glycolysation decrease the activity. ${ }^{17}$ The Iranian study (M Mojarab op.cit) found for the methanolic extract of 14 different Artemisia species a positive correlation between anthocyanidin content and antioxidant activity by the TBA method. Among all A.sieberi has the highest activity. There are other studies which show that Artemisia annua has a lower antioxidant power than other plants of the family, like A ludoviciana. ${ }^{18}$ Concentrations found in polar solvents (water, butanol, ethyl acetate) are higher than in a polar solvents like chloroform. The antioxidant power is proportional to the values of proanthocyanidins found in these different solvents. Being soluble in water they are well present in hot water infusions. ${ }^{19}$ The concentration in decoctions is often higher than in simple infusions. Molecules with a high degree of polymerization, although 
water soluble, probably dissolve in larger quantities in a decoction. In the leaf of tea (Camellia sinensis) the degree of polymerization of proanthocyanidins is only 1.02 and in the stem it is $3,13 .{ }^{20-23}$ If this hypothesis is true, this becomes very important. It was always believed that it was important to make the infusion with $90^{\circ} \mathrm{C}$ water. But Artemisia plants are rich in proanthocyanidins. It would thus be important to use decoctions in lieu of infusions.

\section{Prophylaxis}

Natural, herbal medicine has probably been able to protect humans against tropical diseases in a prophylactic way. More recent anecdotic inputs we received from many of our partners on the prophylactic effect of Artemisisia plants justify more research on this crucial issue. Pharmaceutical companies have over the last 50 years raised tremendous hopes but failed in developing a vaccine against malaria. ${ }^{24}$ If we were able to better understand the polytherapy of plants we might be able to grow and condition them in a more professionnal and hygienic way, present them in a galenic form accessible to poor populations in the most remote places. The WHO opens the door to this ambitious attempt by its WHO Traditional Medicine Strategy 2014-2023 statement and the Nagoya Protocol of 2014. Traditional use refers to documentary evidence that a substance has been used over three or more generations of recorded use for a specific health related or medicinal purpose (WHO/EDM/TRM/2000.1). In this case WHO maintains its position that there is no requirement for pre-clinical toxicity testing. Pre-clinical toxicity testing is only required for new medicinal herbal products which contain herbs of no traditional history of use.

Punica granatum (pomegranate) peels are very rich in proanthocyanidins $1200 \mathrm{mg} / 100 \mathrm{~g} .{ }^{25}$ Another study finds $27600 \mathrm{mg} / 100 \mathrm{~g} .{ }^{26}$ The prophylactic properties of this fruit are well known in India. Since 10 years a home-made biomedicine called OMARIA is on the market. The powder of the sundried pomegranate skin is administered in gelatin capsules in several villages. A report documents the results obtained with 401 patients of all ages. ${ }^{27-29}$ After one year, only 5 people suffered a malaria infection. The vast majority became asymptomatic. During the same period the neighboring villages which were not treated reported and continue to report high incidence of malaria, up to 6 afflictions for the same person, including cerebral malaria. Several individual cases have been continuously followed up for years. There wasn't any indication of resistance to OMARIA. No side effects were noticed, nor antagonism with other antimalarial drugs. The Red Cross Society of the Orissa district is managing the project. Beta-hematin inhibition correlates positively with antimalarial properties A strong beta-hematin inhibition of aqueous extract of pomegranate peels was confirmed (Mutaz Akkawi, Palestine, personal communication). Other research teams study prophylaxis with the fruit rind of pomegranate in Gabon and in Italy. ${ }^{30,31}$

Another plant which has strong prophylactic properties against malaria is Azadirachta indica. ${ }^{32,33}$ Neem is very rich in proanthocyanidins: $6500 \mathrm{mg} / 100 \mathrm{~g} .{ }^{34}$ But it has only very low if any curative and suppressive properties. ${ }^{35}$ Cocoa (Theobroma cacao) was known by the Maya as diet-mediated antimalarial prophylaxis. Based on this anecdotal information prophylactic trials have been started in Ghana by the Ghana Cocoa Board. People are encouraged to daily drink a beverage made by mixing boiling-hot water and natural cocoa powder. ${ }^{36}$ Natural cocoa powder has measurable direct in vitro inhibitory effect on Plasmodium falciparum. This supports anecdotal reports of its ability to prevent malaria, as a result of regular beverage intake. ${ }^{37}$ This has been confirmed by in vivo trials in mice. Cocoa powder was equivalent to chloroquine and has also prophylactic properties ${ }^{38}$ It also raises $\mathrm{CD}^{4+} \mathrm{T}$-cell counts, an effect similar as the one documented by Constant Kansango \& Pierre Lutgen ${ }^{39,40}$ for Artemisia afra. Cocoa powder is effective in attenuating adverse effects of ACT treatment. For example, proved cardio protective and renoprotective potential during artemether-lumefantrine administration. ${ }^{41,42}$

A more recent paper confirms the strong antimalarial properties of aqueous leaf extract of Theobroma cocoa. The effect is very strong against the W2 chloroquine resistant Plasmodium falciparum strain: IC50 of $0.7 \mu \mathrm{g} / \mathrm{mL}$ versus 3.4 for Persea americana and 4.4 for Tridax procumbens, 2 other known antimalarial plants. ${ }^{43}$ Proanthocyanidins are much higher in Theobroma cocoa leaves than in grains: 15\% DW vs $4 \%{ }^{44}$ The Kuna Indians, who reside in an archipelago on the Caribbean Coast of Panama, have very low blood pressure (BP) levels, live longer than other Panamanians, and have a reduced frequency of myocardial infarction, stroke, diabetes mellitus, and cancer. One outstanding feature of their diet includes a high intake of flavanolrich cocoa, which activate nitric oxide synthesis in healthy humans. Nitric oxide (NO) is an important weapon against Plasmodium. ${ }^{45}$ The epicatechin from Theobroma cocoa actively increases nitric oxide synthesis in the body. ${ }^{46}$ Avocado seeds (Persea americana) are rich in proanthocyanidins. ${ }^{47}$ Proanthocyanidins have a strong ferrous ion chelating power and NO production ability. ${ }^{48}$ This may explain the prophylactic power of the drug Artavol $^{R}$ developed by Patrick Ogwang in Uganda. There is growing evidence that arginine, proanthocyanidins present in Artemisia plants and the nitric oxide they generate, interfere with the intrahepatic malaria parasites. ${ }^{49-51}$

Proanthocyanidins differ from most other plant polyphenols because of their polymeric nature and high molecular weight. This particular feature should limit their absorption through the gut barrier, unless membrane carriers are involved. They reach the small intestine almost intact, where they are hardly absorbed because of this high molecular weight. In vitro and in vivo studies using pure compounds as substrates suggest that proanthocyanidins may be degraded into more bioavailable low-molecular-weight phenolic acids by the microflora in the colon. Dimers and trimers are able to cross the intestinal epithelium. Proanthocyanidins are stable during gastric transit in human. Because of their stability they may provide a continuous supply of metabolites..$^{52}$ Saponins well present in Artemisia plants facilitate however the uptake of other materials to which the gut would normally not be permeable. ${ }^{53}$ The fact that tannic acid forms complexes with gelatin might have an impact on the use of gelatin capsules for the administration of powdered leaves of medicinal plants. In as seminal work on simulated digestion Weathers ${ }^{54}$ found that dried leaves in gelatin capsules reduced by $>50 \%$ the amount of artemisinin released in intestinal liquid, but the amount of released flavonoids nearly doubled.

Vegetable oils used as dietary supplementation only moderately reduced the release of artemisinin but doubled the release of flavonoids. The effect of millet or corn on artemisinin release was more pronounced. We would propose as working hypothesis that the tannins present in gelatin capsules or in millet or corn (more than in rice) react with artemisinin, either binding it or acting as probiotics and metabolizing it. The increase in flavonoids noticed in this study (P Weathers op.cit.) might be related to a depolymerization of proanthocyanidins into catechin or gallic acid. Another important 
factor is that tannins enhance the solubilization of hydrophobic molecules and drugs. The solubility of the anti cancer drug docetaxel for example is increased from the $\mu \mathrm{g} / \mathrm{mL}$ level to the $\mathrm{mg} / \mathrm{mL}$ level. ${ }^{55}$ This may also explain the surprisingly high solubility of artemisinin in tea infusions. And the solubility of resveratrol in wine and not in pure water. Proanthocyanidins act like glues and are extracted as adhesives from coffee bran and pine needles. Or from agricultural wastes to produce biological glues in lieu of chemical glues.

Powdered leaves of Artemisia easily produce a sticky mass when wetted, probably because they are rich in condensed tannins. ${ }^{56,57}$ They are used as a protein fixative in electron microscopy. And as it is well known that malaria parasite proteins remodel the host erythrocyte this may be an important factor in antiplasmodial properties. ${ }^{58}$ Hemoglobin acts as binding substrate in the quantitative analysis of plant tannins or in dentistry. ${ }^{59-61}$ They bind precipitate and form complexes with proteins. ${ }^{62}$ This is one of the reasons why they are used in wine fining to remove turbidity. They form insoluble, nonputrescible precipitates with albumin, gelatin, and proteins. It is known since 100 years that gelatin is crosslinked by proanthocyanidin. ${ }^{63}$ This crosslinking effect by proanthocyanidins may affect the specific proteins generated by Plasmodium falciparum to induce changes in the morphology, physiology and function in the erythrocyte host cell. Sporozoites are the infective stage of Plasmodium for the human host. It has been demonstrated that circumsporozoite protein CSP and the transmembranal protein TRAP are essential, insuring the gliding motility for the sporozoite to reach the liver. These proteins uniformly cover the external surface of the sporozoite. ${ }^{64}$

The fact that proanthocyanidins form complexes with proteins may strongly affect the gliding motility of sporozoites. Electron microscopy of sporozoites of the rodent malaria parasite, Plasmodium berghei, reveals electron-dense multilaminate membranous whorls after fixation with tannic acid. ${ }^{65,66}$ They change the 'stick-and-slip' parasite motility supported by TRAP ${ }^{67}$ It is known that reducing the protein content of the diet leads to a decrease in the level of infection. Undernutrition may even protect against severe malarial infection. Binding with proteins proanthocyanidins might thus have a positve effect on malaria. ${ }^{68}$ CPAC Condensed tannins of cranberry and pomegranate reduce the motility of Pseudomonas aeruginosa. The effect of proanthocyanidins on the motility of fish spermatozoides has been demonstrated: a reduction proportional to tannin concentration. ${ }^{69}$ Bacterial motility which plays a key role in the colonization of surfaces by bacteria is also blocked by proanthocyanidins ${ }^{70}$ but it depends on the type: extracts from cranberry are effective, extracts from cinnamon not. Condensed tannins have the ability to reduce the population of protozoa in the rumen of ruminant species. ${ }^{71}$ Some hundred years ago it was found that tannic acid kills Paramecium and other protozoans in waste water. ${ }^{72}$

Several organic acids were used over the same $\mathrm{pH}$ range. Acetic, citric and formic acids elicited responses somewhat comparable to those of the inorganic acids. Pyrogallic and tannic acids proved to have such a high degree of toxicity for Paramecia that reactions within the $\mathrm{pH}$ range studied were impossible, death resulting on contact with the weakest part of the diffusion area. This high degree of toxicity of tannic acid may offer an explanation of the absence of Protozoa from bog (wetland) waters. This is in line with some recent findings at the University Paris Sud. Artemisia annua kills Paramecium tetraurelia. The effect of Artemisia afra is even stronger. A recent study reveals that the human gut bacteria Escherichia coli, normally considered a microbe of pathogenic potential within the host, may help us fend off malaria infection. ${ }^{73}$ Host organisms recognize pathogenassociated molecular patterns, including glycans. During evolution, selective pressures for an effective human immune system result in genetic polymorphisms that prevent the biosynthesis of certain glycans, including Gal $\alpha 1-3 \mathrm{Gal} \beta 1-4 \mathrm{GlnAc}-\mathrm{R}(\alpha$-gal) in humans. Thus, human exposure to common $\alpha$-gal-positive pathogens, including enterobacteria, such as Escherichia coli, induces the production of high titers of circulating antibodies against $\alpha$-gal. A team from Portugal found that Plasmodium falciparum expresses the same glycan molecule as E.coli. It is thus logical to expect that antibodies to $\alpha$-gal cytotoxic to E.coli are also cytotoxic to Plasmodium. Anti$\alpha$-gal antibodies bind to the sporozoite surface, induce their lysis and prevent Plasmodium invasion of hepatic cells. Condensed tannins chelate iron and zinc. ${ }^{74,75}$

Plasmodium falciparum badly needs these metals for its growth and replication. The role of iron is well known, the role of zinc less. The parasite-driven fluxes of weakly bound zinc into infected erythrocytes are essential to pathogenicity. ${ }^{76}$ The Plasmodium falciparum parasite requires acquisition of 30 million zinc atoms before host cell rupture, corresponding to a $400 \%$ increase in total zinc concentration. Highly zinc-specific chelators are shown to inhibit the growth of the parasite while causing an arrest in development at the trophozoite stage. If enough chelator is available survival of the parasite is no longer possible. These chelator treatments result in a depolarization of Plasmodium mitochondria, which suggests a mechanism of chelatorinduced cell death via mitochondrial disruption. But the action of these chelators is slow, up to 48 hours but stable. Proanthocyanidins are prophylactic, but they are also curative. This is the case for many spices and plants, especially the bark or stems of these. ${ }^{77}$

Proanthocyanidins are characterized by a great stability in soil and mammal metabolism. Tannins may inhibit enzyme activity and thus exert a negative effect on microbial growth. A USDA work showed that non-tannin phenolics and hydrolizable tannins are rapidly metabolized. Condensed tannins as for example sorghum tannin are very stable..$^{7-80}$ Condensed tannins are hard to be degraded in both aerobic and anaerobic environnements. ${ }^{81}$ This stability explains their longlasting allelopathy; in the digestive tract and in the conservation of food. ${ }^{82}$ They act more slowly than artemisinin. In a comparative assay on the effect of artesunic acid versus Carica papaya leaf extract the former had strong effect after 4 days and the latter only after 7 days. ${ }^{83}$ It may be the key for the prophylactic effect evident after regular Artemisia tea consumption, even in minor quantities. A permanent reservoir of condensed tannins in the human body.

\section{Acknowledgements}

None.

\section{Conflict of interest}

The author declares that there is no Conflict of interest

\section{References}

1. Liwei Gu, Mark A Kelm, John F Hammerstone, et al. Concentrations of Proanthocyanidins in Common Foods and Estimations of Normal Consumption. J Nutr. 2004;134(3):613-617.

2. Labarbe B, Cheynier V, Brossaud F, et al. Quantitative fractionation of grape pro-anthocyanidins according to their degree of polymerization. $J$ Agric Food Chem. 1999;47(7):2719-2723. 
3. Sunmonu TO, Anthony J Afolayan. Evaluation of Polyphenolic Content and Antioxidant Power. Pakistan Journal of Nutrition. 2012;11(7):520 525 .

4. Laouini SE, Ouahrani MR, Segni L. Influence of solvent extraction on phenolic content, antioxidant and anti-inflammatory activities of aerial parts extract from Algerian Artemisia Herba-alba. J Pharmacy Res. 2016;10(1):58-64.

5. Mehdi M, Seyyed AE, Mohammad HK. Antioxidant activity of methanol extracts of different species of Artemisia from Iran. Pharmacologyonline. 2009;2:797-807.

6. Mazandarani M, Zahra M, Fathiazad F, et al. Essential oil composition, total phenol, flavonoid, anthocyanin and antioxidant activities in different parts of Artemisia annua L. in two localities (North of Iran). Journal of Medicinal Plants and By-Products. 2012;1(1):13-21.

7. Boufennara S, Lopez S, Bousseboua H, et al. Chemical composition and digestibility of some browse plant species collected from Algerian arid rangelands. Spanish Journal of Agricultural Research . 2012;10(1):88-98.

8. Kamel M, Nidhal S, Olfa B, et al. Chemical Composition and Antioxidant and Antimicrobial Activities of Wormwood (Artemisia absinthium L.) Essential Oils and Phenolics. Journal of Chemistry. 2015;804658:1-12.

9. Rosine Chougouo. Study of repellent effect of essential oil extract from the leaves of Artemisia annua cultivated in Cameroon and in Luxembourg. Cameroon: Université des Montagnes; 2016.

10. Laouini SE, Ouahrani MR, Segni L. Influence of solvent extraction on phenolic content, antioxidant and anti-inflammatoryactivities of aerial parts extract from Algerian Artemisia Herba-alba. J Pharmacy Res. 2016;10(1):58-64.

11. Boufennara S, Lopez S, Bousseboua H, et al. Chemical composition and digestibility of some browse plant species collected from Algerian arid rangelands. Spanish Journal of Agricultural Research. 2012;10(1):88-98.

12. Kamel M, Nidhal S, Olfa B, et al. Chemical Composition and Antioxidant and Antimicrobial Activities of Wormwood (Artemisia absinthium L.) Essential Oils and Phenolics. Journal of Chemistry. 2015;804658:1-12.

13. Moroydor Derun E, T Yalcin T, Piskin S, et al. The effect of sodium bicarbonate on the $\mathrm{Mg}$ and $\mathrm{P}$ concentrations in Turkish black and green tea. Int J Scholarly Scientific Res Innov. 2014;8(6):570-573.

14. Smeriglio A, Barreca D, Bellocco E, et al. Proanthocyanidins and hydrilisable tannins: occurrence, dietary intake and pharmacological effects. Br J Pharmacol. 2017;174(11):1244-1262.

15. Wang Y, Zhu JX, Kong LD, et al. Administration of proanthocynidins from grape seeds reduces serum uric acid levels and decreases hepatic xanthine dehydrogenase/oxidase activities in oxonate-treated mice. Basic Clin Pharmacol Toxicol. 2004;94(5):232-237.

16. Rösch D, Angelika Krumbein, Lothar W Kroh. Antioxidant gallocatechins, dimeric and trimeric proanthocyanidins from sea buckthorn (Hippophaë rhamnoides) pomace. European Food Research and Technology. 2004;219(6):605-613.

17. Plumb GW, De Pascual-Teresa S, Santos-Buelga C, et al. Antioxidant properties of catechins and proanthocyanidins: effect of polymerisation, galloylation and glycosylation. Free Radic Res. 1998;29(4):351-358.

18. Isabel SC, Teresa C, Maria B. Phenolic composition and antioxidant capacity of six Artemisia species. Industrial Crops and Products. 2011;33(2):382-388.

19. Laouini SE, Ouahrani MR, Segni L. Influence of solvent extraction on phenolic content, antioxidant and anti-inflammatoryactivities of aerial parts extract from Algerian Artemisia Herba-alba. J Pharmacy Res. 2016;10(1):58-64.
20. Xiaolan J, Yajun L, Yahui Wu, et al. Analysis of accumulation patterns and preliminary study on the condensation mechanism of proanthocyanidins in the tea plant [Camellia sinensis]. Sci Rep. 2015;5:8742.

21. Hanadi AA, Saleh AL, Suhair J, et al. Cinnamon bark water-infusion as an in-vitro inhibitor of $\beta$-hematin formation. Journal of Medicinal Plants Research. 2015;9(38):998-1005.

22. Su-Chen Ho, Pei-Wen Chang. Inhibitory effects of several spices on inflammation. Am J Plant Sci. 2012;3(7A):995-1002.

23. Martins N, Barros L, Ferreira IC, et al. Decoction, infusion and hydroalcoholic extract of Origanum vulgare: different performances regarding bioactivity and phenolic compounds. Food Chem . 2014;158:7380 .

24. Pierre Lutgen. Vaccines, antimalarials and recrudescence. Pharm Pharmacol Int J. 2018;6(2):86-87.

25. Wissam Z, Ghada B, Wassim A, et al. Effective extraction of polyphenols and proanthocyanidins from pomegranate's peel. Int J Pharm Pharm Sci. 2012;4(Suppl 3):675-683.

26. Hamed S Mohammed. Inhibitory effect of tannic acid extracted from grape seeds and pomegranate peels on microorganisms. Mesopotamia Journal of Agriculture. 2008;36(1):12-18.

27. Bhattacharya D, Bhuyan BM, Pradhan PK, et al. Transmission Blocking of Year Round Resistant Malaria in Koraput (India) by OMARIA-A New Antimalarial Phytotherapy. British J Pharm Res. 2012;3(1):54-77.

28. Bhattacharya D. A new natural Antimalaria source in India: A Brief Communication. J Trop Dis. 2015;4:2.

29. Nagendrappa PB, Annamalai P, Naik M, et al. A prospective comparative field study to evaluate the efficacy of a traditional plant-based malaria prophylaxis. J Intercult Ethnopharmacol. 2016;6(1):36-41.

30. Lekana-Douki JB, Deepak Bhattacharya, Rafika Zatra, et al. Indian Anti-Malaria OMARIA Is Effective against African Drug Resistant P. falciparum Field Isolates and Laboratory Strains; without Toxicity. International Journal of Clinical Medicine. 2012;3(1):1-8.

31. Dell'Agli M, Galli GV, Bulgari M, et al. Ellagitannins of the fruit rind of pomegranate (Punica granatum) antagonize in vitro the host inflammatory response mechanisms involved in the onset of malaria. Malar $J$. 2010;9:208.

32. Nagendrappa PB, Naik MP, Payyappallimana U. Ethnobotanical survey of malaria prophylactic remedies in Odisha, India. $J$ Ethnopharmacol. 2013;146(3):768-772.

33. Barlow Benschop NM. The Effect of a Homeopathic Neem Preparation for the Prophylaxis of Malaria-An exploratory trial in an at-home setting in Tanzania. Hungary: Homeopathy; 2006.

34. Pokhrel B, Rijal S, Raut S, et al. Investigations of antioxidant and antibacterial activity of leaf extracts of Azadirachta indica. African Journal of Biotechnology. 2015;14(46):3159-3163.

35. Ofori AK, Oseni LA, Quasie O, et al. A comparative evaluation of in vivo antiplasmodial activity of aqueus leaf extract of Carica papaya, Azadirachta indica, Manifera indica. International Journal of Applied Biology and Pharmaceutical Technology. 2012;3(3):372-378.

36. Addai FK. Natural cocoa as diet-mediated antimalarial prophylaxis. Med Hypotheses. 2010;74(5):825-830.

37. Amponsah SK, Bugyei KA, Gyan BA, et al. In vitro activity of extract and fractions of natural cocoa powder on Plasmodium falciparum. $J \mathrm{Med}$ Food. 2012;15(5):476-482.

38. Jayeola CO, Oluwadun A, Kale OE, et al. Anti-malarial activity of cocoa powder in mice. Afr J Biochem Res. 2011;5(11):328-332. 
39. Aladesemipe OD, Solomon BA, Afolabi O, et al. Antiplasmodial efficacy of crude Cocoa powder extract on CD4 count in P. berghei infected mice. Open J Med Microbiol. 2013;3(3):178-184.

40. Tchandema KC, Pierre Lutgen. In vivo trials on the therapeutic effects of encapsulated Artemisia annua and Artemisia afra. GJRA; 2016;5(6):228234.

41. Asiedu-Gyekye IJ, Seidu MA, N'guessan BB, et al. A dietary strategy for the management of artemether-lumefantrine-induced cardiovascular and renal toxicity. BMC Complement Altern Med. 2016;16:348.

42. Asiedu-Gyekye IJ, Edem Kukuia KK, Seidu MA, et al. Unsweetened Natural Cocoa Powder Has the Potential to Attenuate High Dose Artemether-Lumefantrine-Induced Hepatotoxicity in Non-Malarious Guinea Pigs. Evidence-Based Complementary and Alternative Medicine. 2016;2016:1-11.

43. Komlaga G, Cojean S, Beniddir AM, et al. The antimalarial potential of three Ghanaian medicinal plants. Herb Med. 2015;2:1.

44. Yi Liu, Maximova S, Payne MJ, et al. Proanthocyanidin synthesis in Theobroma cacao: genes encoding anthocyanidin synthase, anthocyanidin reductase, and leucoanthocyanidin reductase. BMC Plant Biol. 2013;13:202.

45. Norman KH, Fisher ND, McCullough ML. Flavanols, the Kuna, Cocoa Consumption, and Nitric Oxide. J Am Soc Hypertens. 2009;3(2):105-112.

46. Redei GP. Encyclopedia of Genetics, Genomics, Proteomics and Informatics. Berlin: Springer; 2008.

47. Chai WM, Wei MK, Wang R, et al. Avocado Proanthocyanidins as a Source of Tyrosinase Inhibitors: Structure Characterization, Inhibitory Activity, and Mechanism. J Agric Food Chem. 2015;63(33):7381-7387.

48. Kim NY, Jang MK, Lee DG, et al. Comparison of methods for proanthocyanidin extraction from pine (Pinus densiflora) needles and biological activities of the extracts. Nutr Res Pract. 2010;4(1):16-22.

49. Shao ZH, Hsu CW, Chang WT, et al. Cytotoxicity induced by grape seed proanthocyanidins: role of nitric oxide. Cell Biol Toxicol. 2006;22(3):149158.

50. Cui X, Liu X, Feng H, et al. Grape Seed Proanthocyanidin Extracts Enhance Endothelial Nitric Oxide Synthase Expression through 5'-AMP Activated Protein Kinase/Surtuin 1-Krüpple Like Factor 2 Pathway and Modulate Blood Pressure in Ouabain Induced Hypertensive Rats. Biol Pharm Bull. 2012;35(12):2192-2197.

51. Nüssler A, Drapier JC, Renia L, et al. L-arginine dependent destruction of intrahepatic malaria parasites in response to tumor necrosis factor. Eur $J$ Immunol. 1991;21(1):227-230.

52. Rios LY, Bennett RN, Lazarus SA, et al. Cocoa procyanidins are stable during gastric transit in humans. Am J Clin Nutr. 2002;76(5):1106-1110.

53. Johnson IT, Gee JM, Price K, et al. Influence of saponins on gut permeability and active nutrient transport in vitro. J Nutr. 1986;116(11):2270-2277.

54. Weathers PJ, Jordan NJ, Lasin P, et al. Simulated Digestion of Dried Leaves of Artemisia Annua Consumed as a Treatment (pACT) for Malaria. J Ethnopharmacol. 2013;151(2):858-863.

55. Jackson JK, Letchford K. The Effective Solubilization of Hydrophobic Drugs Using Epigallocatechin Gallate or Tannic Acid-Based Formulations. J Pharm Sci. 2016;105(10):3143-3152.

56. Christoph MJ, Steve BM, Sungwa M, et al. Bacterial superglue generates a full-length circumsporozoite protein virus-like particle vaccine capable of inducing highand durable antibody responses. Malar J. 2016;15:545.

57. Li G, Smith CS, Brun YV, et al. The Elastic Properties of the Caulobacter crescentus Adhesive Holdfast are Dependent on Oligomers of N-Acetylglucosamine. J Bacteriol. 2005;187(1):257-265.
58. Meek KM, Weiss JB. Differential fixation of poly(L-arginine) and poly(Llysine) by tannic acid and its application to the fixation of collagen in electron microscopy. Biochim Biophys Acta. 1979;587(1):112-120.

59. Maier AG, Cooke BM, Cowman AF, et al. Malaria parasite proteins remodel the host erythrocyte. Nat Rev Microbiol. 2009;7(5):341-354.

60. Epasinghe DJ. Applications of proanthocyanidin in dentistry (Thesis). Hong Kong: University of Hong Kong; 2014.

61. Jack C Schultz, Ian T Baldwin, Philip J Nothnagle. Hemoglobin as a binding substrate in the quantitative analysis of plant tannins. J Agric Food Chem. 1981;29(4):823-826.

62. Van Buren CT, Rudolph F. Dietary nucleotides: A conditional requirement. Nutrition. 1997;13(5):470-472.

63. Kim S, Nimni ME, Yang Z, et al. Chitosan/gelatin-based films crosslinked by proanthocyanidin. J Biomed Mater Res B Appl Biomater. 2005;75(2):442-450.

64. Sultan AA, Thathy V, Frevert U, et al. TRAP Is Necessary for Gliding Motility and Infectivity of Plasmodium Sporozoites. Cell. 1997; 90(3):511-522.

65. Bannister LH, Mitchell GH, Butcher GA, et al. Lamellar membranes associated with rhoptries in erythrocytic merozoites of Plasmodium knowlesi: a clue to the mechanism of invasion. Parasitology. 1986;92(2):291-303.

66. Stewart MJ, Schulman S, Vanderberg JP. Rhoptry secretion of niembranous whorls by Plasmodiuni berghei sporozoites. J Protozool. 1985;32(2):280 283.

67. Song G, Koksal AC, Lu C, et al. Shape change in the receptor for gliding motility in Plasmodium sporozoites. Proc Natl Acad Sci. 2012;109(52):21420-21425.

68. Edirisinghe JS, Fern EB, Target GA. The influence of dietary protein on the development of malaria. Ann Trop Paediatr. 1981; 1(2):87-91.

69. Waltemyer DL. The effect of tannin on the motility of walleye (Stizostedion vitreum) spermatozoa. Transactions of the American Fisheries Society. 1975;104(4):808-810.

70. O’May C, Tufenkji N. The Swarming Motility of Pseudomonas aeruginosa is Blocked by Cranberry Proanthocyanidins and Other Tannin-Containing Material. Appl Environ Microbiol. 2011;77(9):3061-3067.

71. Pineiro-Vasquez AT. Potential of condensed tannins for the reduction of emissions of enteric methane and their effect on ruminant productivity. Arch Med Vet. 2015;47(3):263-272.

72. Johnson WH. The reactions of Paramecium to solutions of known hydrogen ion in solution. Biological Bulletin. 1929;57(4):199-224.

73. Yilmaz B, Portugal S, Tran TM, et al. Gut Microbiota Elicits a Protective Immune Response against Malaria Transmission. Cell. 2014;159(6):12771289.

74. Iffat AT, Maqsood ZT, Fatima N. Study of Formation of Fe(III) with Tanicacid. J Chem Soc Pak. 2004;27(2):174-178.

75. Karamac M. Chelation of $\mathrm{Cu}(\mathrm{II}), \mathrm{Zn}(\mathrm{II})$, and $\mathrm{Fe}(\mathrm{II})$ by tannin constituents of selected edible nuts. Int J Mol Sci. 2009;10(12):5485-5497.

76. Marvin RG, Wolford JL, Kidd MJ, et al. Fluxes in "free" and total zinc are essential for progression of intraerythrocytic stages of Plasmodium falciparum. Chem Biol. 2012;19(6):731-741.

77. Sereme A, Guinko S, Nacro M, et al. Therapeutic power of tannins producing species of Burkina Faso. Pharmacopoeia and African Traditional Medicine. 2008;15:41-49.

78. Allison Kleinberg, Hagermann A, Halvorson J, et al. Biodegradation of polyphenolic's in natural soils. West Virgina: USDA Appalachian Farming 
Systems Research Center; 2008.

79. Jonathan JH, Javier MG, Hagerman AE. Retention of Tannin-C is Associated with Decreased Soluble Nitrogen and Increased Cation Exchange Capacity in a Broad Range of Soils. Lincoln: Publications from USDA-ARS / UNL Faculty; 2013.

80. Adamczyk B, Kitunen V, Smolander A. Polyphenol oxidase, tannase and proteolytic activity in relation to tannin concentration in the soil organic horizon under silver birch and Norway spruce. Soil Biology and Biochemistry. 2009;41(10):2085-2093.
81. Li M, Kai Y, Qiang H, et al. Biodegradation of gallotannins and elagitannins. J Basic Microbiol. 2006;46(1):68-84.

82. Bartosz G. Food antioxidants. Boca Raton: CRC Press; 2014

83. Onaku LO, Attama AA, Okore VC. Antagonistic antimalarial properties of pawpaw leaf aqueous extract in combination with artesunic acid in Plasmodium berghei infected mice. J Vector Borne Dis. 2011;48(2):96100 